\title{
HACIA UNA CARACTERIZACIÓN DE LA TRANSMISIÓN ARISTOTÉLICA EN LA CATALUÑA MEDIEVAL ${ }^{1}$
}

\author{
TOWARDS A CHARACTERIZATION OF ARISTOTELIAN \\ TRANSMISSION IN MEDIEVAL CATALONIA
}

\author{
ÁNGEL ESCOBAR \\ Universidad de Zaragoza
}

\begin{abstract}
Resumen: Sobre la base de una transmisión textual prolongada e intensa como la que se produce en Cataluña -tanto en latín como en catalán- durante la Edad Media y los albores del Renacimiento, el aristotelismo, entendido en el sentido más amplio del término, ofrece en este ámbito una serie de vicisitudes que intentamos analizar sumariamente, atendiendo a sus hitos más definitorios. Esta síntesis, que procura valorar los datos en su contexto peninsular, constituye un pequeño esbozo de la sección que dedicamos al aristotelismo catalán, ya con carácter exhaustivo, en nuestro "Aristoteles Hispanus". Transmisión textual y pervivencia de Aristóteles en España hasta 1600.
\end{abstract}

Palabras clave: aristotelismo catalán; Cataluña medieval; tradición clásica.

\begin{abstract}
On the basis of the prolonged and intensive textual transmission that comes about in both Latin and Catalan in medieval and humanistic Catalonia, Aristotelianism, understood in the broadest sense of the word, offers in that regard a long series of vicissitudes which we try to analyze by considering its main milestones. This summary, which attempts to evaluate the data in a peninsular context, is undertaken as a basis for the exhaustive section about Catalan Aristotelianism which we will present in our "Aristoteles Hispanus". Textual transmission and survival of Aristotle in Spain up to 1600.
\end{abstract}

Keywords: Catalan Aristotelianism; medieval Catalonia; classical tradition.

\section{SUMARIO}

1. Primeros testimonios del Corpus Aristotelicum en Cataluña.- 2. Cauces de disputa aristotélica durante los siglos XIII y XIV.- 3. El caso de Raimundo Lulio y Arnaldo de Villanueva.- 4. El aristotelismo vernáculo.- 5. La eclosión del siglo XV.- 6. Conclusiones provisionales.- 7. Bibliografía citada.

\footnotetext{
${ }^{1}$ Este trabajo se realiza en el marco del proyecto Formas de la épica hispánica: tradiciones y contextos históricos II (Plan Nacional de I+D+i, FFI2012-32231).
} 


\section{Primeros testimonios del Corpus Aristotelicum En CATAluña}

Aun cuando la presencia del Corpus Aristotelicum en Cataluña no haya dejado huellas reseñables de época antigua o tardoantigua, éste se documenta desde muy temprano -en comparación con lo que ocurre en el resto de España- gracias sobre todo al testimonio de Ripoll, un centro relevante para la transmisión de la cultura clásica en nuestro alto medievo y cuya biblioteca llegó a ser una de las más destacables de su época² ${ }^{2}$ La aportación del Monasterio de Santa María de Ripoll en materia aristotélica resulta visible en varios manuscritos todavía conservados y que ya fueron incluidos en su día en el Aristoteles Latinus de Lacombe (Archivo de la Corona de Aragón, Ripoll 83, 115, 128, 134 y 13533). Entre estos Rivipullenses destaca por su antigüedad el Ripoll 83, de finales del siglo X o principios del $\mathrm{XI}^{4}$. Su contenido fundamental (ff. 1r-98v: Boetius in Categorias, ff. 99r-104r: Periermenias ${ }^{5}$ y significativamente, en ff. 104v-117v, el diálogo agustiniano De magistro ${ }^{6}$ ) ha hecho suponer, quizá con escaso fundamento, que podría tratarse de uno de los manuscritos mencionados en el inventario de la biblioteca confeccionado a partir de 1047 y transcrito en un códice hoy deperditus, el Ripoll 407 , bajo la oscura denominación Commentum Boetii super Augustinum uel Aristotelem ( ${ }^{\circ} 238$ en la edición de Zimmermann, como uno de los códices localizados In Montesserate ${ }^{8}$, a continuación de un Porphirium et Augustini [234-235] y de Duo commenta Porphirii [236-237]; los códices en cuestión, fuera cual

\footnotetext{
${ }^{2}$ Puigvert i Planagumà 1995, p. 116 ("només sobrepassada en nombre de volums per la de Toledo, de la qual, pel que fa a la primera meitat del segle XI, no es tenen proves documentals. Només biblioteques com les de Bobbio, St. Gallen, Lorsch, o Reichenau superaven en nombre de manuscrits la de Ripoll"). Según el inventario de 979, la biblioteca albergaba por entonces 65 libros ("Et sunt libri numero LXV et eo amplius", ed. Junyent; "something more than 65 books" entiende Zuccato 2005 , p. 749) y a la muerte de Sunifredo (1008) pudo albergar ya 121 volúmenes (Ibarburu Asurmendi 1999, p. 60).

${ }^{3}$ Se censan además en el Aristoteles Latinus el S. Cugat 51 y el Bibl. Univ. 7.2.6.

${ }^{4}$ Puigvert i Planagumà 2000, p. 48, con lámina del f. 27r, Gros i Pujol 2001, p. 62; muestra decoración similar a la que ofrecen los manuscritos 5 y 27 de Vic, de principios del siglo XI, según Ibarburu Asurmendi 1999, pp. 75-76.

${ }^{5}$ No se trata, por tanto, del comentario de Boecio a Interpr. (Puigvert i Planagumà 2000, p. 48), sino del texto propiamente aristotélico en traducción boeciana (inc. en f. 99r: "Primum oportet constituere quid sit nomen et quid uerbum, postea quid negatio et affirmatio").

${ }^{6}$ En el f. $117 \mathrm{v}$ aparecen transcritos, además, once versos de libro Stacii (= Theb. XII 325-335).

${ }^{7}$ Escrito en el siglo XI o en el XII, desapareció en el incendio de 1835 (Gros i Pujol 2001, p. 51). Beer lo editó críticamente por vez primera (1909-1910, pp. 270-276; $c f$. Zimmermann 2003, II, pp. 1160-1162).

${ }^{8}$ Cf. Puigvert i Planagumà 1995, p. 116, n. 102 (siguiendo a Mundó); Zimmermann 2003, I, pp. 567 y 577. Según Beer 1909-1910, p. 276, estos manuscritos transferidos a Montserrat se encuentran "absolutament perduts".
} 
fuera su número exacto, coinciden con los que había donado Salomón a la biblioteca de Ripoll ca. 1017 en beneficio de su hijo Ermengaudo, con motivo del ingreso de éste en la abadía, según el documento de donación editado por Gros i Pujol' ${ }^{9}$ ).

Beer señaló cómo fray Benito Rivas todavía pudo ver en torno a 1800 el manuscrito aristotélico aludido y anotar su título "completo" (Boëthii et Aurelii Augustini editio super Cathegorias Aristotelis de verbo ad verbum in latinum translatas), y llamó asimismo la atención, unas páginas más adelante, sobre el Parisinus Latinus $2858^{10}$, códice de la segunda mitad del siglo $\mathrm{XI}$, de origen ripollés en el cuaternión que conforman sus ff. 64-71 y que incluye en ff. 64v-66r la transcripción (principio del prólogo) de un Anicii manlii seuerini boecii uiri clarissimi ex consulum ordinibus edici (sc. editio) prima super categorias aristotelis a se uerbum e uerbo translatas de greco in latinum. Jaime Villanueva, por su parte, consignó en su Viage literario (1821) que vio en la abadía otro manuscrito del siglo XI consignado con el número 33 y que contenía las Categorías traducidas por Agustín (Categoriae Aristotelis ab Augustino translatae ${ }^{11}$; expl.: Augustinus tonans divini fulmine verbi / explicuit ampla suo stringens dialectica pugno ${ }^{12}$ ).

En el ya citado inventario de 1047 figuraba previamente un Porphirium grecum (n 76 Zimmermann), que cabe suponer contuviera también, de ser fidedigna la mención, la traducción boeciana de la Isagogué a las Categorías $^{13}$, y unos Topica [111]; se incluían asimismo, ya entre los libri artium, los siguientes títulos, relevantes a nuestro efecto por distintos motivos: [188-189] Ysagoges II, [190] Cathegorias, [191] Peri ermenias, [216] Liber dialectice. Tras la donación de Salomón, el monasterio tenía a su disposición por tanto, como mínimo, un duplicado del repertorio principal para el estudio de la lógica.

\footnotetext{
${ }^{9}$ Gros i Pujol 2001, pp. 61-62, 70 (Porfirium et Augustinum. Duo comenta Porfiri.Commentum Boetii super Augustinum vel Aristotelem). Sobre la probable procedencia ultrapirenaica de los manuscritos $c f$. ibidem, p. 68.

${ }^{10}$ Beer 1909-1910, pp. 235 y 247, respectivamente.

${ }^{11}$ Viage, vol. VIII, 1821, p. 44, donde se indicaba que la obra sucedía al De hierarchia de Dionisio, a la Vita S. Marcialis y a la epístola de Fulgencio De fide ad Petrum diaconum; $c f$. Gros i Pujol 2001, p. 61 (Libro de Porfirio sobre los predicamentos, con signatura I-1-17 Bofarull), Zimmermann 2003, I, p. 568 (donde se indica era el olim Ripoll 80), y II, p. 717.

${ }^{12}$ No obstante, son tres las líneas (sucesión de dos hexámetros y un pentámetro) que suelen concluir la paráfrasis pseudo-agustiniana (Categoriae decem) en algunos códices: "Explicit ampla suo stringens dialectica pugno, / Augustine, tonas divini fulmina verbi, / de quibus humanos perterebras animos" (ed. Minio Paluello, p. 257).

${ }^{13}$ Aludiendo el adjetivo, por tanto, sólo al carácter pagano del autor y no a la lengua del manuscrito (Zimmermann 2003, I, p. 567, junto con II, p. 698); lo contrario habría deparado a Ripoll un ejemplar griego quizá próximo ya en cronología al más antiguo que hoy se conserva: el famoso Vat. Urb. Gr. 35 (ca.900) con anotaciones autógrafas de Aretas.
} 
La posibilidad de que la adquisición de todos estos manuscritos (o su propia copia en Ripoll) se produjera en época temprana se vería reforzada por el hecho de que el periodo comprendido entre la muerte del abad Oliba (1046) y 1070 (vinculación del monasterio al de San Víctor de Marsella) ya no parece haber sido tan idóneo para la incorporación de nuevos códices por parte de la abadía ${ }^{14}$. El origen de los manuscritos, por otra parte, suele considerarse ultrapirenaico y no mozárabe, seguramente con buen criterio, dada la orientación de la abadía en sus relaciones y la enorme penuria bibliográfica que parece haberse producido por entonces en el resto de la Península ${ }^{15}$. Respecto al contexto cultural en que se enmarcaba este interés por la lógica aristotélica cabe seguir citando el trabajo clásico de $B e{ }^{16}$, quien ya remitía al testimonio de Richer de Reims respecto al proceder, heredero del método eriugenista, de su maestro Gerberto de Aurillac (cuya estancia en Cataluña entre 967 y 970 cabe recordar aquí), al recomendar la lectura de la Isagogué porfiriana, de las Categoriae, del De interpretatione y de los Topica ciceronianos, antes de leer algunos poetas latinos principales ${ }^{17} \mathrm{y}$ de pasar, ya con ese bagaje, al estudio de la retórica. Como observaba Beer, se aludía así a una especie de cànon (en realidad una selección en el sentido más estricto: las cuatro obras -Isag., Cat., Interpr. y Top . ciceronianos- que constituían la llamada logica vetus) fácil de encontrar en bibliotecas de Alemania o Francia, pero no en las demás bibliotecas españolas ${ }^{18}$, asoladas como consecuencia de la invasión árabe.

El siguiente referente cronológico de interés en este apartado podría ser el que constituye la biblioteca de la Catedral de Santa María de Urgell en la segunda mitad del XII, según su inventario de 1147 (A. Cap. Urgell, Còdex dels concilis, f. I) ${ }^{19}$, en el que se lee III Libros Fisice... I Porfirium (certainement l'Isagogè, a juicio de Zimmermann ${ }^{20}$, mientras que la obra mencionada en primer lugar sería de contenido astronómico o de cómputo; aunque, en opinión de Gros i Pujol, podría tratarse en principio de la propia Física aristo-

${ }^{14}$ Gros i Pujol 2001, p. 52, Zimmermann 2003, I, pp. 559-561.

${ }^{15}$ En la que las huellas de especulación aristotélica, por lo demás, parecen mínimas; acerca de las Quaestiones de nominibus divinis (inc.: Interrogo ergo quid inter), cf. Leclercq 1949; de la Interrogatio de nobissimo (inc.: Rex Aristotelis Alexandro episcopo) del RAH, Aemilianensis 60 (cuyos estrafalarios interlocutores sólo derivan, a nuestro juicio, de una iconografía de la época mal interpretada) nos ocupamos con detalle en otro lugar.

${ }^{16}$ Beer 1909-1910, pp. 235-236.

${ }^{17}$ Hist. III 46-47 (Quem ordinem librorum in docendo servaverit); sobre la figura de Gerberto es de interés la síntesis de Zimmermann 2003, II, pp. 949-982.

${ }^{18}$ Beer 1909-1910, p. 236, Zimmermann 2003, I, p. 575.

${ }^{19}$ Ibidem, I, p. 597, con transcripción en II, p. 1176.

${ }^{20}$ Ibidem, I, p. 602, II, p. 717, en traducción de Boecio según comparte Gros i Pujol 2005, p. 121; los títulos figuran con los números 81 y 84 , respectivamente, en el desglose realizado por este último autor; edita el catálogo Zimmermann 2003, II, p. 1176. 
télica ${ }^{21}$, esta hipótesis no parece verosímil ni por la descripción del códice, con sólo tres libros, ni por la cronología, demasiado temprana como para presumir que se trate de la versión de Gerardo de Cremona o de la vetus translatio).

Por tanto, es la figura de Boecio, en cuanto transmisor y comentarista de Porfirio y de la lógica aristotélica (y ciceroniana, en virtud de su comentario a los Topica), más que la del propio Aristóteles, la que marca sobre todo este periodo de la transmisión aristotélica en Cataluña ${ }^{22}$, al igual que ocurrió, frente a lo que pasó en Bizancio, en otros muchos centros culturales de la Europa del momento y al calor del mismo interés didáctico ${ }^{23}$. La lógica postboeciana traducida por Jacobo de Venecia a mediados del siglo XII (la de Top., Anal. y Soph. el. sobre todo, saludada con efusión por Juan de Salisbury en Metalogicon III 5) ya no llegó aparentemente a asomar en Ripoll o su entorno. Se trata, en cualquier caso, del primer aristotelismo que podemos documentar con nitidez en la Península.

Los demás testimonios de Ripoll son ya posteriores al siglo XII, pues pertenecen en su mayoría al XIV ${ }^{24}$, y parecen proceder de donaciones como, por ejemplo, las de Ramón Vinader (m. 1351), uno de los grandes coleccionistas medievales de obra aristotélica, tanto del corpus como de sus más variados comentaristas principales ${ }^{25}$. Aparte de los cinco manuscritos catalogados en el Aristoteles Latinus y antes mencionados (Ripoll 83, 115, 128, todavía datable en el siglo XIII y procedente del legado de Vinader, 134 y 135), al menos los veintitrés códices ripolleses siguientes son de contenido aristotélico, ya sea total o parcialmente: 71, 77bis, 84, 95, 109, 120, 129, 131, 132, 141, 142, 144, 148, 150, 161 (la Ética traducida por Alonso de Cartagena, como único texto castellano de cierta extensión documentado en Ripoll), 162, 165, 166, 183, 204, 216, 221, 228. A excepción del 71, analizado en su día por F. de P. Solá (en cuanto importante testigo -quizá de procedencia avignonense- de la Summa logicae de Guillermo de Ockham ${ }^{26}$ ) y del 109, con la célebre Guía del estudiante

\footnotetext{
${ }^{21}$ Gros i Pujol 2005, pp. 120, 124.

${ }^{22}$ Zimmermann 2003, II, pp. 684-686. El Boecio de la Consolatio, como se sabe, se difundirá ampliamente y se traducirá al catalán ya en el siglo XIV, con amplia fortuna.

${ }^{23}$ Así por ejemplo en el Ripoll 42, f. 71r, o en el propio Ripoll 83,f. 3r (con notable advertencia ad marg.: "Aristoteles non de rebus set de sermonibus res significantibus"; $c f$. Zimmermann 2003, II, pp. 716 y 692, respectivamente).

${ }^{24}$ Una sumaria descripción de los manuscritos del fondo, en número de 230 , se halla disponible, junto a su digitalización, en el Portal de Archivos Españoles (http://pares.mcu.es/ParesBusquedas/servlets/Control_servlet [consulta: 13/04/2015]).

${ }^{25}$ Hernando 1995-1996, pp. 14-16.

${ }^{26}$ Como recuerda Tubau 1999, p. 142, es uno de los "dialécticos" que avergonzaba mencionar a Lorenzo Valla, en carta a Joan Serra en 1440 (sobre este agustiniano y antiaristotélico valenciano de la corte de Alfonso el Magnánimo y su De contemplatione amicicie de $1454 \mathrm{cf}$. Cuenca 2013).
} 
entre otros textos de máximo interés, unici aristotélicos en varios $\operatorname{casos}^{27}$, todos ellos requieren todavía una atención pormenorizada, con vistas incluso a la identificación precisa de autores y obras. En su conjunto configuran un fondo rico, de procedencia muy heterogénea y de carácter escolar en su mayor parte (en el que abundan, por tanto, las anotaciones en vernáculo), con un contenido predominantemente lógico y comparable, en este sentido, al que ofrecían otras bibliotecas hispánicas de la época y, en algún caso, ya algo antes ${ }^{28}$.

También la biblioteca del Monasterio de Sant Cugat albergó una pequeña colección aristotélica de interés, siempre con ejemplares de los siglos XIV y XV (manuscritos 10, 34, 41, 51, 54, 58, 69, 75, 82 y 89, según nuestro recuento provisional), entre los que destaca, en cuanto transmisor directo del corpus (parte de Metaph.), el Sant Cugat 51 (s. XIV ${ }^{29}$ ). Es importante el fondo dertusiense, meritoriamente descrito por Bayerri, así como los que, más tardíos, albergan la Biblioteca de la Universidad de Barcelona o la Biblioteca de Cataluña, cuyos contenidos aristotélicos se desglosan en nuestra obra en preparación $^{30}$.

\section{CAUCES DE DISPUTA ARISTOTÉLICA DURANTE LOS SIGLOS XIII Y XIV}

Desde mediados del siglo XIII la Corona de Aragón comenzó a irradiar sus estudiosos, a menudo pertenecientes a órdenes religiosas (particularmente dominicos y franciscanos ${ }^{31}$, con opiniones a menudo muy diversas en materia aristotélica pero siempre activos difusores de la obra del filósofo en todo tipo de formato), y algunos de ellos alcanzaron cierta notoriedad en el campo -por entonces un tanto indiferenciado, causa de principal polémica durante la época- de la filosofía y la teología. La nómina es extensísima y, para muestra, debemos reducirla aquí al máximo.

${ }^{27}$ En general, $c f$. Lafleur 1997.

${ }^{28} C f$., como trabajos clásicos, Gonzálvez 1997, para el caso de Toledo, García Ballester 1996, para el Santiago de las primeras décadas del XIII.

${ }^{29}$ Del Archivo de la Corona de Aragón cabe mencionar, finalmente, los signados como Casa Real 1 y Casa Real 3.

${ }^{30}$ Al respecto sigue siendo de interés la contribución de Robles 1979, así como pequeñas contribuciones diseminadas (como la de González 2011, §47). El Aristóteles de nuestro interés se completa, en buena medida, con el fondo antiguo albergado en bibliotecas valencianas.

${ }^{31}$ Puede remitirse por ejemplo a Robles 1974 y Boadas 2013, respectivamente. Las órdenes legaron, en su conjunto, un rico patrimonio bibliográfico, hoy a menudo desaparecido o disperso. De éstas, como de las muchas referencias aisladas correspondientes a bibliotecas privadas de todo tipo (eclesiásticas, médicas, jurídicas, etc.) y a copia de libros (celosamente analizadas en sus inventarios durante los últimos años, desde el pionero trabajo de Hillgarth referente a Mallorca), no podemos ocuparnos aquí. 
Alumno de Alberto Magno y compañero de Tomás de Aquino fue quizá el dominico Ramón Martí en París ${ }^{32}$, mientras que el también dominico Ferrarius Catalanus sucedió al propio Doctor Angelicus, su maestro hacia 1270, en cátedra de teología $(c a .1274-1276)^{33}$. También serán dominicos el gerundense Nicolás Eimeric (m. 1399) y, ya en pleno XIV y hasta principios del XV, los aragoneses Juan Fort y Juan de Monzón o el valenciano Vicente Ferrer, todos ellos estudiosos, en primer lugar, de la lógica aristotélica.

Trascendental fue asimismo la contribución de los franciscanos del siglo XIV, sobre todo en filas escotistas, como una de las tradiciones teológicas catalanas más notables ${ }^{34}$. Franciscano aragonés fue el influyente Antonio Andrés, y franciscanos fueron Juan Bassols, Guillermo Rubió, discípulo en París de Francisco de Marchia, Pedro Tomás, Pedro de Aragón y, ya entrado el siglo XV, Francisco Eiximenis (m. 1409), Juan Marbres o Pedro de Castrovol.

No es necesario insistir en que hubo otros muchos estudiosos ${ }^{35}$, algunos de muy menor trascendencia pero que, añadidos a las mencionados, reflejan una gran pujanza en el ámbito de la especulación aristotélica. Algo similar ocurría en el ámbito judío, con figuras de relieve excepcional a veces, como Hasdai Crescas.

A finales del siglo XIV comenzaba la inflexión y el Aristóteles más escolástico comenzaba a perder vigor, máxime cuando, tras siglos de polémica, seguía viéndose por muchos como un baldón para la religión cristiana y por otros como un obstáculo para el nuevo estudio científico de la naturaleza que ya comenzaba a apuntar ${ }^{36}$. Una personalidad en cierto modo epigonal como la del dominico valenciano Vicente Ferrer (m. 1419) encarna bien el caso de unos orígenes de rigor escolástico (entre los años 1371 y 1375, en el convento dominico de Lérida) que dieron como fruto su Tractatus de unitate universali y su Tractatus de suppositionibus, desde una perspectiva original aunque inspirada en el tomismo, y que parecen luego abandonados hasta el descreimiento, en aras de la predicación y la vida activa. Nos interesa recordar, en este sentido, su opinión coram populo respecto al pagano "príncipe

\footnotetext{
${ }^{32}$ Sobre la abundante presencia de Aristóteles en su Pugio fidei, de ca. 1287, cf. Robles 1992.

${ }^{33}$ Aparentemente, como apunta Shwartz 2012, p. 71, "Ferrarius often borrowed references to Aristotle and the Fathers from Thomas's writings, without citing the intermediate text".

${ }^{34}$ Una síntesis reciente en Boadas 2009; las obras aristotélicas de algunos de ellos (a veces de gran influjo, también en círculos judíos) han sido objeto de magníficas ediciones recientes, que nos abstenemos de citar.

${ }^{35}$ Cf. por ejemplo Coll 1947, p. 238 a propósito del Convento de la Anunciación de Gerona en el siglo XIII, con dos lectores de lógica: fray Guillermo de Mata qui legat de Logica Veteri y fray Domingo Torpini qui legat de Logica Nova et de Tractatibus. Discípulo de Godofredo de Fontaines fue el carmelita de Perpignan y luego obispo de Mallorca, discípulo de Egidio Romano, Guiu de Terrena, objeto de muy reciente estudio y edición (Fidora 2015).

${ }^{36}$ Valgan así las reflexiones que Puig i Oliver aplicó a Eimeric, en 2006, p. 32.
} 
de los filósofos" (similar en su anacronismo a la que había expresado Lulio mucho antes, por ejemplo en su Doctrina pueril, en cuanto al medieval utrum Aristoteles sit salvatus): Palea, id est sciència Aristòtile, Plató, Dantes, que no valen res ${ }^{37}$. Era el de Ferrer un Aristóteles damnatus por su falta de auténtica virtud, el resabio de una polémica ya vieja (aunque vivamente resucitada aún por el primer humanismo italiano), y que nos permite evocar aquí la poca fortuna que parece haber tenido el "Aristóteles cabalgado" en Cataluña, a diferencia de lo que ocurrió, tanto en la iconografía como en la literatura, en el resto de la Península o en las vecinas Francia e Italia. No hemos sabido localizar aún la figura fuera de Pau de Bellviure (Aristotil ne fou com ancantat, [...] Donchs, si avem per dones folleiat $\left.{ }^{38}\right)$, amoroso suicida nítidamente evocado por Ausiàs March ${ }^{39}$, de Eiximenis, que, tras mencionar los casos de Salomón y Ovidio, parece escandalizarse al reconocer a nuestro filósofo (diu-se) de tal guisa (e Aristòtil diu-se que per dona estec com a bèstia enfrenat e ensellat ${ }^{40}$ ) $\mathrm{y}$, quizá, aunque de manera muy elusiva, del propio March (probable lector, no en vano, del Tresor de Brunetto Latini, transmisor de la leyenda) en XCIX 92: a quatre peus deu anar qui no ho creu.

\section{El CASO de RAimundo LULIO y ARNALDo DE VillanUeVA}

En nuestro recorrido cabe mencionar aparte el caso de dos personalidades coetáneas tan singulares como las de Raimundo Lulio y Arnaldo de Villanueva, vidas paralelas -aunque alguna vez en contacto personal- con abundantes rasgos comunes pese a la diversidad de sus dedicaciones y empeños.

La figura más relevante para nuestro asunto es, sin duda, la del mallorquín Raimundo Lulio (ca.1232-1315), tanto originale quanto isolata, lai-

${ }^{37}$ Cf. Serm. VI 185 (citado en Butiñá, Ysern, Lagarda 2013, pp. 91-92); cabe comparar (ibidem) II 56 ("Aristòtil, on te penses que sie? En infern, que ell llegie en les escoles que ere hun Déu, e anave a l'església e adorave les ydoles, e morí a mala mort"). Será menos rígida la postura de Felip de Malla (m. 1431) respecto a un Aristóteles "qui per gran moralitat de philosophia sabia la sua vida e tot son affer moderar e regir, e humiliant-se a la magestat divina, la qual tantost confessà e conech" (Memorial del pecador remut, III 222-225, citado por Rubio 2009, p. 181; cf. asimismo Rico 2002, p. 160).

${ }^{38}$ Citado en Pagès 1912, p. 234; en general $c f$. Cabré 1998.

${ }^{39}$ Cf. VIII 43-44 (citamos por ed. Archer 1997): "mostrant-me [sc. la verge Maria] clar com han perdut carrer / los qui en amor de les dones han via", LI 33-40: "Savis són cells qui les festes no colen / d'aquelal amor qui en les dones cau; / ab deslleals sovent elles han pau, / lleixant aquells qui per ben amar moren. / En record és aquell Pau de Bellviure / qui per amar sa dona tornà foll; / tal camí tenc, soptat rompent lo coll. / De tot mon dan dubte'm no us veja riure" (verso final, previo a la Tornada, que también evoca el escarnio del lujurioso como elemento típico de la leyenda aristotélica en cuestión).

${ }^{40}$ Citado por Montoliu 1959, p. 37. 
co autodidatta, estraneo agli ambienti dell'università ${ }^{41}$. Pese a este marcado carácter autodidacta (aunque acaso no tan ajeno a las polémicas universitarias como se ha supuesto) y a la absoluta peculiaridad de su reflexión aristotélica, que nunca descendió a la exégesis o al comentario, su repercusión fue amplísima, hasta poder afirmarse que se trata probablemente, junto con Domingo Gundisalvo y Pedro Hispano, del más universal de nuestros "aristotélicos" medievales, por encima de figuras como las de Gonzalvo Hispano o Ferrandus de Hispania.

El aristotelismo de Lulio experimentó una clara evolución, de modo que quien comenzara limitándose a recomendar un canon natural de Aristóteles (Doctrina pueril) y fuera luego maestro de silogismos en París, al igual que tantos otros escolásticos de su tiempo ${ }^{42}$, pasó a ser émulo y a considerarse finalmente superador del filósofo. Esta afirmación última se ha propuesto a menudo, con toda razón, considerando la alegoría de su vida que su discípulo Thomas Le Myésier (m. 1336) hizo representar con lujo de detalles en las miniaturas de su Breviculum seu Electorium parvum del manuscrito de la Badische Landesbibliothek, St. Peter perg. 92: Lulio, precedido de la cruz y sobre su caballo Recta intentio (miniatura VII, en f. 7r), concluye y culmina la labor de Aristóteles, a lomos de Ratiocinatio, y del hereje Averroes, que cabalga sobre Imaginatio. En su conquista de la Verdad, Lulio daba por fracasado el precedente pagano y se erigía como héroe de un nuevo realismo, de una nueva lógica (inventiva y no meramente deductiva, como ha solido resumirse ${ }^{43}$ ) y, en última instancia, de un nuevo orden político y cultural. Nos interesa destacar aquí cómo la caracterización fisiognómica de Lulio, también supervisada a buen seguro por su fiel Le Myésier, pasa de ser en el transcurso de pocos folios la del maestro medieval de aspecto monacal y sentado in cathedra (como muy a menudo se había representado al propio Aristóteles tanto en ámbitos cristianos como arábes y judíos ${ }^{44}$ ), a la de un sabio de luengas barbas y tocado característico, de impronta oriental, pero que muestra una efigie preleonardiana muy similar a aquella con que se representará al propio Aristóteles en época humanística y renacentista (sobre todo a raíz del hallazgo de su supuesto

${ }^{41}$ Cf. Bianchi, Randi 1990, p. 10, así como el propio testimonio del pensador en el Liber de experientia realitatis Artis generalis de 1308, recordado por Soler 2006, p. 53, n. 2: “Confiteor, quod ego Raimundus sum illitteratus, et per Artem generalem multos libros feci, forte plus quam centum, Dei semper gratia ministrante". Sobre su oposición hacia los dominicos, pese a no constar su observancia franciscana, $c f$. Hillgarth 1971, p. 250.

${ }^{42}$ Imagen evocada por Higuera 2001, pp. 93-94.

${ }^{43}$ Sobre algunas claras influencias del aristotelismo árabe peninsular en Lulio, $c f$. Lohr 1987, pp. 78, 82; el resultado fue, según la síntesis de Lohr (ibidem, p. 88), que "Actio ist nicht wie bei Aristoteles ein Akzidens, sondern sie wird als substantiell verstanden". Para el posible fundamento "físico" del dinamismo luliano, $c f$. ahora Higuera 2014.

${ }^{44} C f$. Hillgarth 1971, pp. 451-452 y lám. IV. 
busto por parte de Ciriaco de Ancona en Samotracia, en $1444^{45}$ ), si bien con una gestualidad mucho más dinámica y acorde con el espíritu luliano. Pese a haberse sostenido que Lulio, como el Metge de Lo somni (mucho después, según ha de advertirse ya), puso a Platón por delante de Aristóteles, como consecuencia del agustinismo de fondo latente en el mallorquín ${ }^{46}$, no hemos hallado todavía en su obra datos que apoyen expresamente esta predilección, más allá de lo que pueda deducirse de la siempre sugerida "desafección" de Lulio hacia nuestro filósofo.

En la Doctrina pueril (ca. 1274-1276), redactada originalmente en catalán, Lulio negaba desde un punto de vista general, en cuanto privados de fe y de la voluntad de tenerla, tanto a Aristóteles como a Platón y demás filósofos paganos ${ }^{47}$. Esto no le impedía, a continuación, erigir a Aristóteles, lo philosof, como prototipo de los maestros en materia de ciencia natural, formulando su canon aristotélico (y pseudo-aristotélico), compuesto de Metaph., Phys., Cael., Gener. corr., Meth., An., Somn. vig., Sens., De anim. y Plant. ${ }^{48}$. Aunque la selección luliana responde a la más habitual en la época, también en el hecho de que las obras propiamente naturales vayan precedidas de la Metafísica ${ }^{49}$, ofrece pequeñas singularidades. Así cuando agrega el adjetivo racional al título tradicional del De anima ${ }^{50}$ (lo libre de Anima racional, en cap. 19); era convencional en la época referirse a los tres tratados sobre el sueño como De somno et vigilia, pero, en cualquier caso, cabe preguntarse, a la vista del título propuesto y de su síntesis (En lo libre de dormir e vetlar parla de la natura e de la proprietat per la qual los animals dormen e vetlen), si Lulio también recomendaba a su hijo los referentes al ensueño y a la adivinación (Insomn. y Div. somn.); finalmente, también debe repararse en que el De sensu (libre de sintent e sentit) se menciona, frente a lo que era frecuente en la transmisión, tras su selección de los Parva naturalia (en la que omitía referirse de manera expresa, por ejemplo, al De memoria, pese a ser asunto tan esencial en su reflexión ${ }^{51}$ ).

${ }^{45}$ Sigue vigente al respecto Lehmann-Hartleben 1943.

${ }^{46}$ Butinyà 2011a,pp. 24-25.

${ }^{47}$ DP 75, 7, p. 135 Obrador; la opinión de Lulio prefiguraba bastante la mantenida por Petrarca en relación con el concepto pagano de "felicidad", basado en la ética aristotélica (Boccassini 2007).

${ }^{48}$ DP 77, 13-22, pp. 139-141 Obrador. La ausencia de la Ética, señalada por algunos estudiosos (como la de los tratados lógicos, añadiríamos, entre otros), se debe, como es obvio, a que el canon se restringía expresamente al Aristóteles "natural".

${ }^{49}$ Wingate 1931, pp. 21-22.

${ }^{50}$ El rasgo es advertido y comentado por López Alcalde 2012, p. VIII, n. 6

${ }^{51}$ Además de hacer referencia al pseudo-luliano Liber ad memoriam confirmandam, cabe recordar que el luliano mallorquín Bernat Garí escribirá un Art memorativa (1338) hoy no conservada. Sobre la mnemotecnia de corte aristotélico de la gramática hebrea del pensador Profiat Duran, de 1403, cf. Novoa 2010, p. 28. 
La amplia obra de Lulio tiene en cuenta casi el conjunto del corpus aristotélico, ya sea por vía directa o indirecta ${ }^{52}$, unas veces para asumir sus postulados más conocidos y otras para introducir innovaciones al servicio de una doctrina general de gran calado. Terció en las polémicas más vivas de su época, a menudo, también él, desde un notable anacronismo de corte medieval en la consideración de las doctrinas aristotélicas de aplicación teológica. Así, décadas después de que el enigmático Mauritius Hispanus y otros "heterodoxos" hubieran sido acusados de torcer el pensamiento del filósofo, Lulio defendía los 219 capítulos de la condena de 1277 frente a un imaginario interlocutor llamado "Socrates" en su Declaratio Raimundi per modum dialogi edita, compuesta en 1298. También fue notable su contribución al atacar en sus obras parisinas de 1310-1311 a aquellos que Tomás de Aquino (a partir de su De unitate intellectus adversus Averroistas, de 1270) y otros estudiosos, como el teólogo franciscano Pedro de Juan Olivi, ya habían calificado como Averroista ${ }^{53}$, defensores de postulados básicos como el de la eternidad del mundo, la unidad del alma o la doble verdad. Destacan en este sentido su Disputatio Raimundi et Averroistae (1310) o el pseudo-luliano De erroribus Averrois et Aristotelis de 1310-1311, que, como rasgo de interés, incluía referencia expresa de los lugares aristotélicos en cuestión. Fue por entonces cuando Lulio, que ya había etiquetado su lógica como nova (1303), en cuanto basada en su propia Ars, redactó en París (1310) su Metaphysica nova et compendiosa o su Liber novus physicorum et compendiosus. Su éxito en la Universidad de París fue al final muy relativo, pese a la innovación de su método filosófico y a su propia batalla en el ámbito político ante Felipe IV y el Concilio de Viena (1311-1312), no llegando a conocer la prohibición de las doctrinas de Averroes de 1323 o el relevo que, tras su peculiar interpretatio humanística, asumirá Petrarca en el ataque contra canem illum rabidum Averroim, qui, furore actus infando, contra dominum suum Christum contraque catholicam fidem latrat ${ }^{54}$.

${ }^{52}$ Respecto al Organon cf. Higuera 2009, p. 396; por su parte, Bonillo 2006, pp. 397-398, ha señalado la posible influencia de las Auctoritates Aristotelis en Lulio.

${ }_{53}$ Imbach 1987, p. 262, recordó cómo Lulio criticaba desde 1298 a los "novi philosophi qui sunt sequaces antiquorum philosophorum", por el hecho de ser "causa dissensionis". En la Declaratio, Lulio "discute ideas averroístas aunque, como constataron Steenberghen y Cécile Bonmariage entre otros, en ningún momento de la obra aparece el término averroísta ni Averroes para nombrar la doctrina que se rebate" (López Alcalde 2010, p. 353). El Liber de anima rationali, también de ca. 1310, fue quizá su primera obra antiaverroísta (López Alcalde 2010 , p. 352).

${ }^{54}$ Epist. seniles XV 6 (ed. 1554,p. 812); cf. Bordoy 2009. Es mucho lo escrito sobre lulismo, post-lulismo y pseudo-lulismo en general; sobre las figuras, excepcionales, de Ramon Sibiuda, Fernando de Córdoba (uno de los casos más interesantes de asunción foránea del lulismo), Pere Daguí o el franciscano Bernard de Lavinheta $c f$. Ramis 2013. Interesa destacar aquí, asimismo, que Cisneros fundó una cátedra de filosofía y teología lulianas en la Universidad de Alcalá. 
Ya fuera su origen aragonés, valenciano u otro cualquiera, el médico Arnaldo de Villanueva (ca. 1235/1238-1311/1313) es con bastante probabilidad el científico medieval de ámbito catalán ${ }^{55}$ que, conociendo sólo rudimentariamente el griego, muestra mayor influencia del Aristóteles latino en su obra. Su rica biblioteca personal albergaba al menos una Ética y una Metafísica ${ }^{56}$. Según el reciente estudio de Grau Torras (ib.), de sus numerosas citas aristotélicas cabe concluir que conocía Cat., Top. y Anal.post., así como Mete., Gener. corr., Phys., An., Metaph., De anim. y Parv. nat. (particularmente Somn. vig.); también utilizó el Secretum secretorum, fuente del Regimen sanitatis, y los Problemata. Las citas, que facilitaba por lo general sin incluir su localización en el corpus y sin literalidad alguna, se concentran sobre todo en el Tractatus de intentione medicorum (ca. 1290), en el Commentum supra tractatum Galieni de malicia complexionis diverse (ca. 1290/1295) y en el Tractatus de humido radicali (ca. 1295/1300), redactados durante su ejercicio como docente en Montpellier.

Nos interesa destacar aquí dos rasgos que entendemos aproximan el aristotelismo de Arnaldo al de su contemporáneo, y a menudo compañero de fatigas en materia política, Lulio. Por una parte, la concepción eminentemente práctica de su disciplina. Según la definición -calcada del principio del Canon de Avicena- de su Speculum (ed. 1504, cap. I, f. 1ra), la medicina es para Arnaldo scientia y no ars, y va dirigida a la sanación de los enfermos: scientia cognoscendi dispositiones humani corporis in quantum sanabile et conservandi sanitatem inventam in eo et restituendi deperditam quantum possibile fuerit ${ }^{57}$. Esta misma orientación práctica es la que le lleva en muchas ocasiones a contraponer o, en la medida de lo posible, conciliar las doctrinas médicas concretas de Aristóteles y Galeno. En estrecha consonancia con lo anterior, destaca el carácter profundamente antiescolástico de su pensamiento, orientado hacia una teología de práctica cristiana (desprovista de "glosa" aristotélica alguna) y manifiesto desde un punto de vista teórico, en la línea del franciscano Buenaventura, en su Gladius iugulans thomatistas (es decir, expositores secundum Thomam) de 1304: el niu d'Aristòtil [= París, sede del Anticristo aristotélico] s'enderrocarà $i$ serà buidat... ${ }^{58}$

\footnotetext{
${ }^{55}$ Según Benton 1982, p. 246, a pesar de su carácter absolutamente cosmopolita "he was by 'nationality' a Catalan (...) the only language in which he wrote besides Latin was Catalan". No ha de confundirse con el Arnaldus Catalanus, también del XIII, mencionado por Lohr 1967, s. v., con actividad sobre el De anima.

${ }^{56}$ Grau 2014, p. 66, quien recuerda que poseía además un "libellus super quartum metaurorum".

${ }^{57}$ Citado en Mensa 2009, p. 39.

${ }^{58}$ Citado por Colomer 1997, p. 42 y n. 52; $c f$. Mensa 2009, p. 36. Sobre el carácter antitomista y platonizante de nuestro médico puede remitirse a Calvet 2003.
} 
No es extraño, en tal medida, que en sus obras teológicas apenas cite la obra de nuestro filósofo ${ }^{59}$.

Mucha menor trascendencia que Arnaldo tuvo el singularísimo comentarista aristotélico conocido como Guillermo de Aragón, pese al extraordinario interés de su obra en materia onírica y fisiognómica (muy recientemente explorada a fondo), y tampoco es comparable, por ejemplo, la que alcanzó Ramón Sibiuda, autor de un Liber creaturarum redactado entre 1434 y 1436, entre otras obras de corte filosófico, no menor enemigo que sus mencionados antecesores, desde una perspectiva platonizante, de las depravaciones escolásticas y capaz de denunciar incluso la ociosidad de la propia obra aristotélica a efectos de práctica teológica ${ }^{60}$.

\section{EL ARISTOTELISMO VERNÁCULO}

Es difícil calcular cuál pudo ser la penetración del Aristóteles indirecto en Cataluña (vía Cicerón, Séneca, Casiodoro, Agustín, Isidoro, etc.) a través de textos vernáculos de época más o menos temprana ${ }^{61}$. Sí puede afirmarse que las traducciones catalanas de textos aristotélicos (o, más bien, pseudo-aristotélicos) comienzan a documentarse desde finales del siglo XIII, en el marco del mismo proceso que afectó a algunos textos de ciencia y medicina, según ha estudiado Cifuentes aduciendo motivos de varios tipos, como son el decisivo reinado de Jaime II (1291-1327) o la existencia de un público lector especializado profesionalmente y bien dispuesto a relegar el latín ${ }^{62}$ (a diferencia de lo que habría ocurrido en Castilla, escorada además desde tiempos de Alfonso X hacia materias como la astronomía y la astrología ${ }^{63}$ ). Aunque el factor no deba sobrestimarse, suele insistirse también en cómo el ascendiente luliano, con su sanción definitiva del catalán como lengua de expresión filosófica, pudo constituir un notable apoyo en la misma dirección. A continuación nos limitamos a ofrecer una brevísima síntesis del problema,

${ }^{59}$ Mensa 2009, p. 42.

${ }^{60}$ Citado por Puig i Oliver 1978, p. 132: "Quia Philosophus Aristoteles fecit octo libros Physicorum, et ad probandum solum hoc, scilicet Deum esse, et etiam fecit in Metaphysica duodecim libros ad probandum Deum esse. Sed liber Bibliae incipit in hoc, quod dicit Deum esse, et ibi facit suum principium sine probatione".

${ }^{61} C f$. Cifuentes en su suplemento de 2007 (http://www.sciencia.cat/suplements.htm, ad p. 159 [consulta: 13/04/2015]), a propósito del Isidorus de 1293 recogido como n ${ }^{\circ} 52$ en el inventario de la biblioteca real de 1410 .

${ }^{62} C f$. Cifuentes 2007, 1997, p. 41, respectivamente; esta última opinión ha sido suscrita por Faulhaber 2004, p. 877.

${ }^{63} C f$. Faulhaber 2004, p. 875. Se recoge material de interés a este respecto en Alberni 2012. 
aún pendiente de numerosas clarificaciones; para el detalle debe recurrirse al utilísimo repertorio de Cabré - Ferrer (Cens de traduccions al català medieval fins a 1500), con información actualizada.

El Pseudo-Aristóteles sapiencial y moralizante del Secretum secretorum (al margen del de la Política o la Ética, todavía por descubrir) es el primero en documentarse ${ }^{64}$ (las versiones del De pomo, de Eth. y de Oecon. llegarán ya en el siglo XV). Se conservan traducciones catalanas de las versiones larga (u oriental) y corta (u occidental) del Secretum. La versión larga se conoce al menos en dos versiones: por una parte el Llibre del secret dels secrets, traducción quizá anterior a 1322 y elaborada a partir de la latina de Felipe de Trípoli (la más difundida, pese a conservarse hoy en tan sólo tres testigos, entre ellos el Matr. 921, de 1385, ff. 1r-30v); por otra el Llibre de regiment de senyors o Secret dels secrets, del tercer cuarto del siglo XV (sólo conservada en el Matr. 1474 , ff. 1-55 ${ }^{65}$ ). Según se consigna en el inventario de Cabré - Ferrer, sembla que va existir almenys una altra versió catalana del Secretum també derivada de la versió de Felip de Trípoli a jutjar per un inventari de 1464 (Zamuner 2005: 71) ${ }^{66}$. La versión corta se integró en traducción catalana, junto con otras fuentes, en el Llibre de doctrina o Llibre de saviesa, elaborado durante el reinado de Jaime I o de Jaime II $^{67}$, antes de 1323 (cuando Jaime II ya disponía de un ejemplar); se elaboró a partir de la Poridat de las poridades castellana, anterior a 1260, y se conserva tanto en el Matr. 921 (ff. 31v-43r) como en el Escor. M.I.29, ff. 1-15 (siglos XIV-XV) ${ }^{68}$.

Del original árabe del Liber de pomo (o De morte Aristotelis) hubo traducción resumida hebrea del judío barcelonés ibn Hasday (1235), a partir de la cual surgió la latina de Manfredo y de ésta la catalana anónima de mediados del siglo XV (única conocida en la Península y sólo conservada en el Matr. 1474, ff. 105-112 $\mathrm{v}^{69}$, bajo el título La mort d'Aristòtil o Paraules d'Aristòtil en l'hora de la seva mort $^{70}$ ).

Guillem de Copons tradujo del francés el Libro del Tesoro de Brunetto Latini en 1418 y, con él, el compendio de la Ética a Nicómaco de Herman

\footnotetext{
${ }^{64}$ Se hace referencia a una traducción catalana del Secretum perteneciente a la Orden del Temple (ca.1300-1326) en Iglesias 1996, p. 16.

${ }^{65}$ Pudo influir en la traducción aragonesa de Fernández de Heredia (Escor. Z.I.2), como lo hace en otras posteriores, pero es cuestión todavía oscura (Cabré, Ferrer 2014, p. 50).

${ }^{66}$ Cabré, Ferrer 2014, p. 50.

${ }^{67}$ Cifuentes 2002, p. 176.

${ }^{68}$ Acerca de la Epistula Aristotelis ad Alexandrum, que ya circuló en recensión versificada en occitano del siglo XIII, $c f$. Cifuentes 2002,pp. 98, 173.

${ }^{69} \mathrm{El}$ texto latino se encuentra, por ejemplo, en el manuscrito $B U 573$.

${ }^{70}$ Heusch 1992; Cifuentes 2002, p. 181. Interesa destacar aquí su presencia en el Ripoll 148 (s. XIV), ff. 194v-208v, tras unos Dicta philosophorum. Como en algunos manuscritos latinos, carece de prólogo y de primer parágrafo.
} 
el Alemán que éste contenía ( $B C$ 357, ff. 1-293v). Hay además traducciones parciales de la Ética, pertenecientes asimismo al siglo XV. Hacia 1463-1464 se redactó probablemente el compendio anónimo editado por Cuenca i Almenar (a partir del único manuscrito que lo conserva, el $B C$ 296, ff. 1-132 $\mathrm{v}^{71}$ ), para el que se ha propuesto tanto una dependencia del texto aragonés correspondiente como lo contrario. Al tercer tercio del XV pertenece asimismo el florilegio de la Ética comprendido en el Gerona, Biblioteca Pública, ms. 9/97, ff. $43 \mathrm{v}-55 \mathrm{v}^{72}$.

De Oeconomica hay traducción catalana de Martí de Viciana (14771492), elaborada sobre la latina realizada por Bruni a partir del griego hacia 1420; se conserva en el Escor. d.III.2, ff. 91-115 (finales siglo XV-XVI).

Otras obras de influencia aristotélica de interés para este apartado son, por ejemplo, las siguientes:

- Se tradujo al catalán, como única versión medieval en vulgar de que se tiene noticia, el Dragmaticon philosophiae de Guillermo de Conches (mediados del siglo XII), bajo el título de Summa de filosofia; es traducción anónima anterior a 1338 (se ha sugerido que podría coincidir con un Libre de philosophia copiado en 1302 para Jaime II) y figura en el inventario real de $1410^{73}$.

- Consta la presencia de una Suma de col-lacions de Juan de Gales, traducción de su Summa collationum o Communiloquium (ca.1265-1270), en un inventario de 1428, si bien hay referencias a la obra en la Corona aragonesa desde principios del XIV. La traducción aragonesa (Rams de flores, en el Escor. Z.I.2) procede del escriptorio de Juan Fernández de Heredia, donde se copia entre 1385 y 1393; este florilegio y la traducción castellana (Suma de colaciones o Libro del gobernador, en el Matr. 12181), con texto próximo al del $B C 265$ (siglo XV), derivarían de una traducción aragonesa perdida realizada a su vez a partir del catalán. Por otra parte, el Breviloquium de virtutibus antiquorum principum et philosophorum se tradujo como Breviloqui o breu parlament dels antics prínceps e philòsoffs en el siglo XV (ante 1458).

- El carmelita Arnau Estanyol tradujo y glosó hacia mediados del siglo XIV (antes, probablemente, de 1381) el De regimine principum de Gil de Roma como Llibre del regiment dels prínceps; el maestro Aleix, de ca. 1480 (mestre Aleix... regint les scoles en dita ciutat [= Barcelona], según el colofón de la edición de 1480), corrigió y adaptó al catalán más moderno la traducción de Estanyol; asimismo redactó o retocó glosas de carácter escolástico al final

\footnotetext{
${ }^{71}$ Cuenca 2012.

${ }^{72}$ Cf. http://mcem.iec.cat/veure.asp?id_manuscrits $=601$ [consulta: 13/04/2015].

${ }^{73}$ Cifuentes 2002, p. 178.
} 
de cada capítulo, algunas de las cuales fueron traducidas al navarro-aragonés y añadidas a una copia de la Visión deleitable (Matr. 3367, ejemplar quizá del Príncipe de Viana ${ }^{74}$ ).

- La Visión deleitable de Alfonso de la Torre fue traducida por el mallorquín Francesc de Prats (ca. 1470), según el manuscrito conservado en Ripoll, descubierto y descrito por G. Avenoza; hay una segunda recensión anónima (Visió delectable) del texto catalán originario en incunable imprimido en Barcelona en 1484 por Mateu Vendrell ${ }^{75}$.

- Quesits atribuidos a Alberto Magno impresos en Barcelona $1499^{76}$ y que son traducción del Liber de homine de Girolamo Manfredi (publicado en Bolonia en 1474 y elaborado sobre la base de los Problemata pseudo-aristotélicos).

No podemos detenernos en otras obras de cierta trascendencia para nuestro tema ${ }^{77}$, ni, ya en general, en la inmensa cantidad de obras en catalán donde se citan textos aristotélicos, en latín o asimismo en catalán, que requieren todavía estudio detenido y que no dejan de ser muestra, en todo caso, de la extensa difusión a que venimos haciendo referencia en estas páginas.

\section{LA ECLOSIÓN DEL SIGLO XV}

En los albores del Renacimiento, tras el "prehumanismo" de Fernández de Heredia y su entorno, la herencia de nuestro filósofo sigue siendo un desafío asumido en el ámbito catalán desde personalidades y sensibilidades muy distintas, al tiempo que los textos seguían circulando de mil maneras (a menudo ya alojados en bibliotecas privadas, en ejemplares a veces difíciles de identificar hoy, y, desde finales del XV, en incunables). La ausencia de un humanismo filológico dedicado a Aristóteles (tanto latino como griego) es 2012.

${ }^{74}$ Kiviharju 1995, pp. 16-17; de Aleix de Barcelona se ha ocupado recientemente Bescós

75 Cifuentes 2002, pp. 181-182. El manuscrito catalán conservado se encuentra desde 1931 en Ripoll, Casa de la Cultura, Sign. Lambert Mata XX, y parece, a la vista del papel, de ca. 1470 (Avenoza 1999, p. 278; la ausencia de interdependencia entre ambas versiones se subraya ibidem, pp. 286-288).

${ }^{76}$ Cifuentes 2002, pp. 100-101.

${ }^{77}$ Es el caso de las obras albertianas y pseudo-albertianas, el de múltiples tratados sobre vicios y virtudes o el de obras tan heterogéneas como la materia troyana, Las Partidas, el De anatomia vivorum atribuido a Ricardo Ánglico (m. 1252; Cifuentes 2002, p. 138), el Liber de moribus del dominico italiano Jacobo de Cessulis (con dos traducciones catalanas medievales, una de ellas en el Matr. 925) o el Liber de vita et moribus philosophorum del Pseudo-Burley (hay traducción catalana de la versión italiana anónima impresa en Venecia, 1480, la cual incorpora, entre otros materiales, fragmentos de la traducción de Laercio realizada por Ambrogio Traversari en 1433). 
tan evidente en Cataluña como en el resto de España. En cualquier caso, ha querido verse la huella de un cierto humanismo en la obra, tan distante aparentemente del nuevo movimiento, del Doctor Dulcifluus (Antonio Andrés) o en la actividad de Pedro de Castrovol, que editará en Lérida y Pamplona obras de Aristóteles traducidas por Bruni ${ }^{78}$.

En realidad, todo autor de la época medianamente formado había recibido enseñanzas aristotélicas. Dejando al margen figuras como la del dominico valenciano Antoni Canals (m. 141979), o referencias literarias como las presentes en el Tirant, destacan quizá, como ha solido reconocerse, las de Eiximenis, Metge y March.

El franciscano gerundense Francesc de Eiximenis se forma en el extranjero (en Oxford, París o Toulouse, estancia tras la cual escribirá ya su Tractat d'usura, ca. 1379, con un puñado de citas aristotélicas siempre tomadas de segunda mano ${ }^{80}$ ) y produce su obra sobre todo, tanto en latín como en catalán, en Valencia, donde vive entre 1382/1384 y 1408. Poseyó una pequeña biblioteca aristotélica, rastreada en su día por J. Monfrin. Su tradición más propia es la escolástica y las citas aristotélicas afloran en buena parte de su obra, con especial relevancia en contextos políticos y éticos, a menudo con su localización precisa. De nuestro somero análisis de sus citas, deducimos que casi siempre se trata de un uso de Aristóteles como autoridad a la vieja usanza, usada con frecuencia por vía indirecta y de corte más medieval que humanístico (Diu Aristòtil que..., aunque ya no siempre cosa verdadera a juicio del eclesiástico).

Bernat Metge es ya uno de los primeros humanistas claros de la Península, quizá sobre todo por su pronto acercamiento a la obra de Petrarca, a raíz de su estancia como secretario regio en Avignon (1395 ${ }^{81}$ ) con acceso a la magna biblioteca de Benedicto XIII. Seguramente poseía sus conocimientos en materia de dialéctica ${ }^{82}$; su aristotelismo no es sin embargo de gran presencia y se limita en buena medida a la reflexión en torno al alma (ese continuat moviment perdurable, como glosa el término endelecheia, sobre nítida base

\footnotetext{
${ }^{78}$ Gensler 1997, p. 61 ("it is thanks to Thomas Aquinas that Antonius acquires classical erudition, which misled Carreras y Artau to see his Metaphysics commentary as an early humanist work") y Boadas 2009, p. 57, respectivamente.

${ }^{79}$ El prefacio de Canals a su traducción del pseudo-bernardiano Liber de modo bene vivendi ad sororem ha llamado la atención a este respecto; en su De arte memorativa expositio (un comentario en antiguo provenzal al De arte memorativa luliano) sólo dos veces cita a Aristóteles, "de passada i mig per formulisme" ( $c f$. Colomer 1997, pp. 77-78).

${ }^{80}$ Hernando 1991, p. 38.

${ }^{81}$ Cardelle de Hartmann 2011, p. 109.

${ }^{82}$ Gómez 2010, p. 14.
} 
ciceroniana, en $\operatorname{Lo~somni~}^{83}$ ), ya que en otros casos los ecos aristotélicos parecen ser todavía más de acarreo ${ }^{84}$.

Interesa destacar aquí cómo en Metge se plantea de pasada una cuestión que empezaba a resurgir con vigor en la época (también en esto se advierte su inquietud humanística), como era, más que la de la posible conciliación entre Platón y Aristóteles (aspiración antigua y tardoantigua, arrastrada en Occidente desde Boecio), la de la posible jerarquización de ambos. El petrarquista Metge parece admitir expresamente en Lo somni la supremacía de Platón, al afirmar, en I 8, que Aristóteles fue "el más próximo a la verdad después de Platón" (Aristòtil, que aprés de Plató s'acostà més a la veritat; trad. J. Butiñá). Es posible, aunque no nos parece probable, que el pasaje, con fuentes de corte agustiniano bastante literales (Civ. Dei VIII 5) retomadas con amplitud por Petrarca (De ignor., cap. IV), sea deliberadamente ambiguo en su expresión (ya que el sintagma aprés de Plató podría significar en principio, en un sentido puramente cronológico, "siguiendo a / después de Platón"), como parece sugerir Fenzi en su reciente estudio sobre el tema; en cualquier caso, no se trata de una mera mención de términos yuxtapuestos y más o menos intercambiables, como la que se encontrará algo después en el anónimo Curial e Güelfa (vol. III, p. 78 Aramon: Lexats Aristòtil e Plató e venits a $m i$ ?), ni de un juego de palabras poco afortunado basado en el viejo amicus Plato, ni, quizá, de una opinión acotada al asunto del alma. Como también ha apuntado Fenzi, es posible que Metge no desee en realidad oponer ambas figuras, transmisoras de mera "opinión” en materia teológica, y que, con Petrarca (mediatizado por su propia demonización del vulgo y la escolástica, ya que a maioribus Plato, Aristotiles laudatur a pluribus ${ }^{85}$ ), se limite a declarar

\footnotetext{
${ }^{83} \mathrm{Su}$ interés por el tema del alma se ha puesto en relación con Crescas, discípulo de Nissim de Gerona (Harvey 1990, p. 55, donde parece excluirse Aristóteles como fuente directa, si bien Metge alude esporádicamente al filósofo: $c f$. Butinyà 2011b).

${ }^{84}$ Así en el caso de la cita de Tiresias en Lo somni III 24 ("Fembra és animal inperfect, de passions diverses desplasents e abhominables passionat, no amant altra cosa sinó son propri cors e delits"), que sigue muy de cerca Il Corbaccio de Boccaccio. El referente aristotélico (y luego tomista) será también sólo un trasfondo ya en la poesía de March o en Pere Torroella (desde una perspectiva occitano-catalana en De las calidades de las donas, esp. 92: "que se dize hombre imperfecto", frente a lo que se observa en el Razonamiento en deffensión de las donas, 27, 25-27, sosteniendo, con apoyos de teoría médica, que "Aquel convenible medio que entre estos se falla ningún natural orden contrasta que en las mugeres segunt que en los hombres no pueda avenir"; en general $c f$. Archer 1999-2000).

${ }^{85}$ De ignor. IV 41; cf. Rer. mem. I 26 (ed. G. Billanovich): "Accedit quod quecunque ferme de ipsius laudibus dici possunt, iam vulgo et scolasticis omnibus nota sunt", o, como destacaba al margen durante su lectura del Fedón en el Paris. Lat. 6567A, "bonos quidem et malos quam paucos esse utrosque, medios autem plurimos" (a propósito de Phaed. 90a, en f. 20r, según observó Minio-Paluello 1972, p. 91). Que Petrarca recababa su juicio acerca de Platón y Aristóteles de todo tipo de fuentes lo confirma el propio autor en el capítulo mencionado de Rer. mem.: "Accepimus a Grecis hodie etiam apud eos Platonem propter ingenii singularem
} 
la mayor sabiduría de Platón en términos generales y sin necesidad alguna de ostentar mayor observancia platónica ${ }^{86}$.

La recepción aristotélica fue bien distinta en el caso del poeta valenciano Ausiàs March. Considerado ya en el siglo XVI como poeta "filósofo" (por ejemplo por parte de su traductor al castellano, Baltasar de Romaní, en la princeps de $1539^{87}$ ), la poesía de March destaca ciertamente, entre otros motivos, por el tono escolástico que la informa en su conjunto y que la hace casi inconfundible, sin parangón en la lírica peninsular ${ }^{88}$. Oposiciones tan medievales como la de "substancia" y "accidente" 89 " potencia" y "acto" afloran en su poesía de manera frecuente, junto con otros muchos conceptos o términos de raigambre aristotélica ${ }^{90}$ pero, a menudo cribados por el tomismo, de trasfondo cristiano y particularmente agustiniano ${ }^{91}$. El caso del "justo medio" o in medio virtus (vale decir, bonum) es, en este sentido, paradigmático en la reflexión del poeta ${ }^{92}$ y casi parece querer sustentar por sí solo toda una moral práctica en torno al amor de voluntat bona y regido por un casi moderno comú seny $y^{93}$ (aunque fuera una aspiración acaso imposible de realizar en el fondo,

quandam altitudinem divinum, Aristotilem vero propter scientie ubertatem demonium dici”. En general $c f$. ahora Bosch-Veciana 2013.

${ }^{86}$ Fenzi 2012. Que Metge tuviera acceso en Avignon al Platón que pudo estar en manos de Petrarca (Paris. gr. 1807, A) parece, en principio, muy dudoso.

${ }^{87}$ Como observa Lloret 2013, pp. 20-21, el exordio de Romaní comienza con cita de la $\mathrm{Me}$ tafísica, quizá cruzada con otra procedente de EN VI 13.

${ }^{88} C f$. últimamente Icardo 2010, que analiza ese gusto por la "escolástica en verso" que March potencia al máximo, ya sugerido por Johnston 1978, p. 384.

${ }^{89}$ Es célebre, por ejemplo, el paradójico pasaje de XCII 191-192: “Accident és amor, e no substança / e per sos fets se dóna a nós conéixer"; para descartar cualquier posible filiación aristotélica directa de la etiqueta baste remitir a Heiple 1983, con remisión a las fuentes médicas (diagnósticos como el del propio Arnaldo de Villanova) y líricas correspondientes (Guido Cavalcanti, Cino da Pistoia, Dante...).

${ }^{90}$ Como el de hàbit ( $c f$. LXXVII 4, 25-28, con su bello trasunto garcilasiano en el soneto XXVI, y, particularmente, CXVII).

${ }^{91} C f$. Mestre 2009, mostrando sobre todo que la estructura ternaria del alma, con su dimensión racional, sensitiva y vegetativa, sostenida por Santo Tomás de Aquino, sólo se documenta una vez en toda la obra de March (CXVII 129-132: "Res sens esguard no és d'hom pròpia cosa, / car general és als bruts e als arbres; / del sentiment lo brut a l'arbre avança, / e la raó a l'hom d'aquells separa"). Frente al alma vegetativa que comparten vegetales, animales y hombres, March se limita a señalar la falta de razón común a animales y vegetales, sobre la base del poema IV; la simple oposición entre cuerpo y alma se recoge, no obstante, sólo algo más adelante, en vv. 145-148).

${ }^{92}$ Cf. XXX 31-32: "car la virtut en lo mig lloc se met / e los extrems per vicis abandona", LVIII 33-34: "Sobresamor dos extrems me procura, / e lo mig d'ells no pusc haver trobat", LXXII 15, etc. Sobre el tema versa también, en última instancia, el famoso poema IV, como recreación del tema del asno de Buridano, bien glosado por Cuenca 2005, pp. 41, 43.

${ }^{93} C f$. XLV 25-26: "Aquella amor que's diu voluntat bona / e solament esguarda part honesta", frente al "altr'amor", 33-35: "Aquesta amor per nostres senys nos entra / e fa present al comú seny, e passa / lo presentat, per sos migs, a l'entendre", así como Cabré 1996, p. 55, n. 37. A propósito de CXX, 17-28 y el principio "excellens sensibile corrumpit sensum" debe 
ya que En carn sens carn viu qui pel mig camina, / e no.n veu hom qui vajen per tal via [CXIII 145-146], y dada también la exigencia de la humana natura, que, de no templarse, se convierte en apetit brutal [IV 30]). Era un terreno explorado durante siglos por mentes de toda condición, lleno de adherencias y totalmente minado desde el punto de vista retórico y literario.

Por lo demás, convendrá insistir en que la terminología no era siempre inequívoca y en que las tradiciones y convenciones también se entrecruzaban gustosamente. Así, pese a la sutil filiación aristotelizante que se ha sugerido por ejemplo para la etiqueta plena de sen $y^{94}$, cabe recordar que en la mente del lector culto de la época podía yuxtaponerse una simple sapiens horaciana (Carm. I 11) de carácter muy distinto en principio; los poemas CXXIIa y CXXIIb, con su célebre contraposición entre amor y caza (es decir, amor o caza) a cargo de un poeta que fue falconer major del Magnánimo, se podían asociar, en principio, con tópicos latinos de procedencia muy similar a la anterior (Hor., Carm. I 1 26: venator tenerae coniugis inmemor); lo superfluo de honor y diners (CVI 23 y 24), frente a los deleites naturales asociados a la "mantenencia" (la spècia sostinent), no se aprendía por entonces sólo en la Ética aristotélica, sino también seguramente, por la vía de la predicación, en el Salomón de 1 Reg. 3, 11-12, del mismo modo que, para situar al Crates de XVIII $41-44^{95}$, se pudo evocar también en determinado momento al paisano de Mat. 13, 44-46, por no ir al agustiniano pondus meum amor meus y similares. Muchos de los viejos tópicos fueron quizá aristotélicos en un principio, dentro de la tradición literaria, pero ya se habían cubierto de retóricas muy diversas y no menos eficaces.

Las referencias específicas de March a la figura de Aristóteles son muy escasas y siempre de apariencia bastante tópica: XXVI 41-42 ¿ ¿On és l'enginy d'Aristòtil trobat, / d'Orígenes, Sèneca e Plató? $\left.{ }^{96}\right)$, CVI 143-144 (lo

leerse el fino análisis de Cabré, ibidem, con alusión a los pasajes del De anima implicados y sus comentarios medievales (ya que, como se indica, en p. 55, "some nuances in March's poem, which are indebted to the Aristotelian commentary tradition, give us a clearer idea of the level of his knowledge").

${ }^{94}$ Cuenca 2005, p. 54: "S'ha d'entendre el senyal d"aquest poema, com (...) plena de saber la manera concreta de conduir-se envers la felicitat natural" (v. 57).

${ }^{95}$ Para el símil de Crates, $c f$. Cuenca 2008, p. 43, con referencia al correspondiente pasaje de $E N$.

${ }^{96}$ Naturalmente, la referencia al talento aristotélico (ingenium) no tiene por qué depender del Rhythmus de contemptu mundi de S. Bernardo (PL 184, 1315: vel Aristoteles summus ingenio), como supuso Pagès 1912, pp. 283-284, 287, n. 1, ya que aparece en multitud de fuentes (como las petrarquistas, entre otras). Retomará el adjetivo Felip de Malla, en el lugar antes citado, quizá sobre base agustiniana (Civ. Dei VIII 12: "cum Aristoteles Platonis discipulus, uir excellentis ingenii et eloquio Platoni quidem impar, sed multos facile superans"): "aquell il-lustre príncep dels philòsophs, pare de la secta dels peripatètichs, mestre del gran Alexandre, home de excel·lent enginy". 
filosof açò pren per error, / dient d'aquest no estendre tant ses mans) y, esta vez también con una imagen quizá menos favorable de Platón que de Aristóteles, 233-240 (Plató volc dir que bo ni cominal / no és delit, mas hac molts enemics: / picurians posaren, com inics, / que l bé de l'hom era en delit carnal. / Mas darrer venc son deixeble mateix / que anul-là vanes opinions, / e del que dix donà evidents raons / i el bon delit de l'àvol divideix). Como se sabe, es discutida todavía la autenticidad de otro poema (CXXVIII) en el que se remite de manera muy directa a la obra de nuestro filósofo y, más concretamente, al libro VI de la Ética a Nicómaco (vv. 156-16197): D'açò pus llarg no parlaré: / lo gran filòsof vos acús, / qui n'ha tocat e no dessús. / (tot llarg en l'Ètica ho diu / en lo sisè; temps ha que ho viu, / jo m'acord bé com hi està). Otras posibles alusiones son más vagas, como ocurre en el caso de CVI, 89-92.

Al margen de lo que puedan indicar estas referencias internas, suele hoy aceptarse que March no refleja un sistema filosófico reconocible y que pocos lugares calificados como "aristotélicos" en su obra van más alla del lugar común en la época ${ }^{98}$, si bien distintos estudiosos han aludido a pasajes que sugieren un uso concreto de Aristóteles, en la senda ya marcada en su día por Pagès: Nul doute qu'Auzias March ait connu directement Aristote et Sénèque $e^{99}$.

En cuanto a las fuentes concretas de su aristotelismo poco ha podido avanzarse con total claridad. Francisco Rico, basándose en la imagen que abre el poema CI (Lo viscaí que s troba en Alemanya), se refirió con toda verosimilitud a la posible procedencia clerical de parte de su fraseología (Pedro Marín en ese caso), fundada así en la predicación ${ }^{100}$. Es una vía que, sin duda, debe seguir explorándose. En referencia al ámbito menos popular, Cabré ha señalado cómo se documenta en la Valencia del siglo XV un gran interés del público laico hacia la filosofía natural y moral ${ }^{101}$, mientras que también se ha aludido, en otra dirección, al posible influjo de la estancia de Alfonso el Magnánimo en Valencia entre 1425 y 1431.

Por lo demás, son pocos los datos concretos que aporta la reconstrucción de su propia biblioteca. Se ha aludido con frecuencia al Tresor de Brunetto Latini, existente en francés en la biblioteca de su padre, que Archer ve

\footnotetext{
${ }^{97}$ Ramírez 1980, p. 499.

${ }^{98} C f$. últimamente Di Girolamo 2004, pp. 39-40.

${ }^{99}$ Pagès 1912, p 374 (quien añadía: "Pour Platon et Épicure, il ne semble en avoir lu que des extraits dans quelque recueil analogue à celui de Jean de Galles"); baste remitir a los pasajes aludidos ibidem, por ejemplo en pp. 288, 296, 306, 353; así, según Archer 1991, p. 59, "és indiscutible la presència d'idees netament peripatètiques" en el poema XXXII.

${ }^{100}$ Rico 1982, XXII.

${ }^{101}$ Cabré 1996, p. 52.
} 
detrás, por ejemplo, de XXXII 9-12 $2^{102}$. Pere March también tenía una Summa collationum de Juan de Gales, importante testigo de tradición indirecta aristotélica ${ }^{103}$. Sin embargo, los datos son oscuros en un caso de particular interés para nuestro asunto, concerniente al tratado de su biblioteca que comenzaba secundum quod dicit Filosopus in secundo de anima y que Pagès renunció a intentar identificar por lo inespecífico de su inicio ${ }^{104}$. La secuencia puede hallarse, ciertamente, en múltiples lugares; sirvan de ejemplo los dos siguientes, pertenecientes a las Quaestiones super libro de animalibus Aristotelis de Pedro Hispano: Secundum quod dicit philosophus in secundo De anima, quod data est uirtus generatiua ut quod non poterat saluare in se, saluetur in suo simili $^{105}$ (...) secundum quod dicit philosophus in secundo De anima, et huiusmodi priuationem motus possibile est ponere in quolibet; pero aceptar esta identificación (u otra similar) haría suponer un inicio trunco poco verosímil en principio, o bien que se tratase de un simple repertorio escolar o florilegio, lo cual tampoco constituye un gran avance.

Pese a reconocer que "el filósofo" por antonomasia era Aristóteles, Cantavella ha sugerido que podría tratarse de una referencia al Dragmaticon de Guillermo de Conches ${ }^{106}$, aduciendo que se trata de un diálogo en el que intervienen Dux y Philosophus y que el capítulo 25 del libro VI se titula De anima hominis. El argumento parece poco determinante, y tampoco parecen muy verosímiles otras propuestas que se han realizado ${ }^{107}$. Cabré sugirió la posibilidad de que se tratase del De potentiis animae de Walter Burley (también atribuido en algún manuscrito a Roberto Grosseteste), cuyo incipit suele ser Ut dicit Philosophus secundo de anima potentiarum animae quibusdam animatis insunt omnes potentiae ${ }^{108}$. En principio, y siempre por la vía de la aproximación, una posibilidad más constituirían por ejemplo las Quaestiones super sophisticos elenchos de Simón de Faversham, cuyo incipit es Sicut dicit philosophus secundo de anima potentiae distinguuntur per actus ${ }^{109}$, si bien

${ }^{102}$ Archer 1991, pp. 61-63, consideró más verosímil el empleo de la traducción de Guillem de Copons que de la latina de Grosseteste. La relación de March con el Príncipe de Viana, cuya traducción no parece emplear (Pagès 1912, p. 307), ha sido objeto de discusión, y Cabré 1996, p. 51, n. 17 , ha llegado a poner en duda el casi siempre atendible testimonio de Zurita.

${ }^{103}$ Pagès 1912, p. 322.

${ }^{104}$ Pagès 1912, p. 115; Cabré 1996, p. 52, n. 24, remite a Valencia, Arxiu del Regne, Protocols de Berenguer Cardona, 1459, 2, f. 10v.

${ }^{105}$ Cf. Navarro 2009, quaest. I 2, p. 117, y quaest. II 2, p. 122.

${ }^{106}$ Cantavella 2010, p. 99, n. 15.

${ }^{107}$ Así, que se trate del comentario a la Ética de santo Tomás, como alguna vez se ha sugerido (Cabré 1996, p. 50, n. 13).

${ }^{108}$ Cabré 1996, p. 52.

${ }^{109}$ Lohr 1995, p. 133. También un sermón anónimo contenido en el Paris. Lat. 3553 (f. 32v y ss.) se inicia "Sicut dicit Philosophus in secundo De Anima, quaedam non videntur...". 
el tema del tratado parece aún menos próximo que el antes mencionado a los posibles intereses de March. Como bien resumen las Auctoritates Aristotelis, el libro segundo del De anima ofrecía múltiples lugares sobre los que se especuló muy abundantemente durante toda la Edad Media (intellectus separatur ab aliis potentiis animae sicut perpetuum a corruptibili, actus activorum sunt in patiente praedisposito, excellens sensibile corrumpit sensum, etc. ${ }^{110}$ ), y la continuación del breve e inexpresivo incipit conservado permanece, por desgracia, aún en la sombra.

Con la apuesta escolástica de March, tan acertada en lo lírico como difícil de rastrear en lo filosófico, y el declinar del siglo XV terminaba en cierto modo una larga etapa de transmisión aristotélica en Cataluña. Durante el siglo XVI continuarán las grandes líneas de especulación in Aristotelicis: a la labor de las grandes figuras, como Juan Luis Vives o Pedro Juan Núñez, se unirán un sinfín de contribuciones mayores o menores, procedentes del campo de la docencia, tanto en Barcelona como en Valencia ${ }^{111}$, del de la traducción ${ }^{112}$, del de la creación literaria, del de la predicación ${ }^{113}$ o del del comentario (todavía muy vigente, gracias a trabajos como los de Ángel Estanyol, Juan de Celaya, Lluís Joan Vileta, Antonio Jordana, Antonio Sala, Jerónimo Jorba ${ }^{114}$, etc.).

\section{CONCLUSIONES PROVISIONALES}

En cuanto movimiento de profundo calado cultural, el aristotelismo medieval debe analizarse a la luz de lo ocurrido con la tradición clásica en su conjunto y con el humanismo en general. Pese a la complejidad del tema, casi imposible de abordar de manera tan sumaria, para el caso catalán suscribiríamos plenamente las páginas introductorias de Luis Gil a su Humanismo valenciano $^{115}$, reflejo de sus fundadas opiniones respecto al humanismo español en general, heredero de una parádosis interrumpida dramática e irreversiblemen-

\footnotetext{
${ }^{110}$ El libro segundo del De anima es base, por ejemplo, de la glosa 22 de Aleix ( $c f$. Kiviharju 1995, pp. 100-101).

${ }^{111}$ Bastará citar nombres como el de Pedro Juan Olivar, que explicará dialéctica en París, o el de Juan Gélida, profesor de filosofía en la misma ciudad.

${ }^{112} C f$. por ejemplo López Rueda 1973, p. 122, a propósito de Juan Bautista de Monllor y su traducción de los Anal.pr.

${ }^{113}$ Según muestra, por ejemplo, el Montserrat 68, con los Sermons de Antoni Alfaig, m. 1572 , provistos de abundantes citas aristotélicas ( $c f$. http://mcem.iec.cat/veure.asp?id_manuscrits=622 [consulta: 13/04/2015]).

${ }^{114}$ Sobre los tres últimos $c f$. López Rueda 1973, pp. 141-142.

${ }^{115}$ Gil 2003, pp. 13-17.
} 
te por la invasión árabe y de una política cultural tan despiadada y miserable en términos históricos como fue, durante largos siglos, la hispánica.

La transmisión de Aristóteles en Cataluña (y, en general, en la Corona de Aragón) durante la Edad Media y hasta finales del siglo XV fue amplia, como demuestra el rico patrimonio manuscrito e impreso todavía hoy conservado y que procuramos censar con detalle en nuestro Aristoteles Hispanus. Desde un punto de vista tipológico, presenta muchos rasgos en común con lo que ocurre en el conjunto de la Península durante el mismo periodo; así, por citar dos de los principales, la cronología en la recepción del corpus (lógico, natural y ético, sucesivamente; el de carácter poético quedará ya, en sus muy escasas muestras, para el siglo XVI ${ }^{116}$ ) o la ausencia casi absoluta de un humanismo filológico (es decir, del humanismo por excelencia) de primer rango.

Si se trata de observar diferencias, también cabría quizá reparar en varias a partir de este modestísimo estado de la cuestión; así la ausencia en Cataluña de ciertos proyectos comunes y de ciertas polémicas que influyeron más en Castilla, como fueron la protagonizada por Bruni en torno a la traducción ${ }^{117}$, la referente a la oposición entre Platón y Aristóteles (que también hemos visto apuntar, no obstante, en Metge o March) o, ya en las postrimerías, la referente al problema moral que planteaba la esclavitud, al calor de la conquista de América.

Aunque sea con excesiva brevedad, hemos procurado destacar el peso del vernáculo, que determina una parte muy importante del aristotelismo en Cataluña, así como la presencia de personalidades aisladas deslumbrantes, como la descollante de Lulio, cuya trayectoria (al igual que la de Arnau de Vilanova, en su terreno) pone de manifiesto, además de una cierta idiosincrasia cultural y de un carácter peculiar, otra obviedad: la de que Cataluña estaba más abierta a Europa y al Mediterráneo (como en el siglo XVI mostrará también la difusión del erasmismo y del ramismo) que el resto de la Península, aunque, por desgracia, se encontrara a veces igual de lastrada que ese resto peninsular -y por similares motivos- en materia de transmisión textual y pervivencia literaria del saber antiguo (aristotélico, por ejemplo).

\footnotetext{
${ }^{116}$ Ha recibido ya atención entre nosotros, por ejemplo, el Sant Cugat 69 , ff. $127 \mathrm{v}-134 \mathrm{r}$, con sus conocidas Annotations per a entendre alguna cosa de l"arte poetica de Aristotil ( $c f . \mathrm{http} / / /$ mcem.iec.cat/veure.asp?id_manuscrits=462 [consulta: 13/04/2015]).

${ }^{117}$ Sobre el posible conocimiento de la polémica por parte de Martí de Viciana $c f$. Martínez 2009; acerca del valenciano Francisco Escobar, quien según Andrés Schott había comenzado a traducir la Retórica de Aristóteles por no satisfacerle las versiones anteriores de Trapezuntio y Hermolao (por defectuosas e inexactas respectivamente), cf. López Rueda 1973, p. 141.
} 


\section{BIBLIOGRAFÍA CITADA}

Alberni, Anna (ed.) (2012), El saber i les llengües vernacles a l'època de Llull i Eiximenis. Estudis ICREA sobre vernacularització, Barcelona, Abadia de Montserrat.

Archer, Robert (1991), Una font aristotèlica d'Ausiàs March, en Ferrando, Antoni; Hauf, Albert G. (eds.), Miscel-lània Joan Fuster. Estudis de Llengua i Literatura, IV, Valencia, Universitat de València - Barcelona, Publicacions de l'Abadia de Montserrat, pp. 59-74.

Archer, Robert (1997), Ausiàs March. Obra completa, 2 vols., Barcelona, Barcanova.

Archer, Robert (1999-2000), Las coplas De las calidades de las donas de Pere Torroella y la tradición lírica catalana, "Boletín de la Real Academia de Buenas Letras de Barcelona" 47, pp. 405-423.

Avenoza, Gemma (1999), El manuscrito catalán de la Visión deleitable de A. de la Torre, en Fortuño Llorens, Santiago; Martínez Romero, Tomàs (coords.), Actes del VII Congrés de l'Associació Hispànica de Literatura Medieval (Castelló de la Plana, 22-26 de setembre de 1997), vol. I, pp. 275-292.

Beer, Rudolf (1909-1910), Los manuscrits del Monastir de Santa Maria de Ripoll, "Boletín de la Real Academia de Buenas Letras de Barcelona" 5, pp. 492-520.

Benton, John F. (1982), The birthplace of Arnold of Vilanova: a case for Villanueva de Jiloca near Daroca, "Viator" 13, pp. 245-257.

Bescós Prat, Pere (2012), Aportacions a l'estudi de tres traductors catalans quatrecentistes: Ferran Valentí, Arnau d'Alfarràs i Aleix de Barcelona, "Iberoromania" 75, pp. 232-249.

Bianchi, Luca; Randi, Eugenio (1990), Le verità dissonanti. Aristotele alla fine del Medioevo, pref. de Mariateresa Fumagalli Beonio Brocchieri, Roma - Bari, Laterza.

Boadas Llavat, Agustín (2009), Joan Duns Escot i els escotistes catalans, "Enrahonar" 52, pp. 47-63.

Boadas Llavat,Agustín(2013),Trovadores, filósofos y traductores franciscanos catalanes a través de los siglos, en Bueno García, Antonio (coord.), La labor de traducción de los franciscanos, Madrid, Cisneros, pp. 263-280.

Boccassini, Daniella (2007), I sogni di Aristotele e l'ombra di Dante: riflessioni sulla fenomenologia della visione nel De ignorantia di Petrarca, "Italica" 84, pp. 137-161.

Bonillo Hoyos, Xavier (2006), Edició crítica i estudi dels llibres I, II, IX i X del Llibre de meravelles de Ramon Llull, Barcelona, Universitat de 
Barcelona (tesis doctoral) (cf.http://www.tdx.cat/handle/10803/1682 [consulta: 13/04/2015]).

Bordoy Fernández, Antonio (2009), Ramón Llull y la crítica al aristotelismo parisino de finales del siglo XIII: en torno a la cuestión de la pluralidad, "Revista de Hispanismo Filosófico" 14, pp. 25-41.

Bosch-Veciana, Antoni (2013), Les referències a Plató en el De sui ipsius et multorum ignorantia de Francesco Petrarca, "Revista Catalana de Teologia" 38, pp. 415-438.

Butinyà, Júlia (2011a), Al voltant del concepte de l'home en el Libre de meravelles. (Rere la projecció de Llull), "Estudis de llengua i literatura catalanes" 62 [Miscel·lània Albert Hauf, 1], Barcelona, Abadia de Montserrat, pp. 9-36.

Butinyà, Júlia (2011b), "Què veets en la difinició de la ànima racional que no pogués ésser dit de les ànimes dels bruts?" Tècniques humanístiques de Lo somni (I), "eHumanista" 18, pp. 267-286.

Butiñá Jiménez, Julia; Ysern i Lagarda, Josep-Antoni (coords.) (2013), Adentrándonos en la literatura catalana. Edad Media, Madrid, UNED.

Cabré, Lluís (1996), Aristotle for the layman: sense perception in the poetry of Ausias March, "Journal of the Warburg and Courtauld Institutes" 59, pp. 48-60.

Cabré, Lluís (1998), Notas sobre la memoria de Santillana y los poetas de la Corona de Aragón, en Deyermond, Alan (ed.), Cancionero. Studies in Honour of Ian Macpherson, Londres, Queen Mary and Westfield College, pp. 25-38.

Cabré, Lluís; Ferrer, Montserrat (eds.) (2014), Cens de traduccions al català medieval fins a 1500, en http://translatdb.narpan.net/ [consulta: 30/07/2014].

Calvet, Antoine (2003), Recherches sur le platonisme médiéval dans les auvres alchimiques attribuées à Roger Bacon, Thomas d'Aquin et Arnaud de Villeneuve, "Revue des sciences philosophiques et théologiques" 87, pp. 457-498.

Cantavella, Rosanna (2010), Sobre la poesía antifemenina de Ausiàs March: el poema 71, "Revista de literatura medieval" 22, pp. 85-104.

Cardelle de Hartmann, Carmen (2011), Die Leser des "Secretum" im 15. Jahrhundert außerhalb Italiens. Beobachtungen anhand der Handschriften, "Beiträge zur Geschichte der Deutschen Sprache und Literatur" 133, pp. 100-120 (http://dx.doi.org/10.5167/uzh-47939 [consulta: 13/04/2015]).

Cifuentes i Comamala, Lluís (1997), "Translatar sciència en romans catalanesch": la difusió de la medicina en català a la Baixa Edat Mitjana i el Renaixement, "Llengua \& Literatura" 8, pp. 7-42. 
Cifuentes i Comamala, Lluís (2002), La ciència en català a l'Edat Mitjana $i$ el Renaixement, Barcelona, Universitat de Barcelona - Palma de Mallorca, Universitat de les Illes Balears (la segunda ed., de 2006, incluye addenda en pp. 411-454; un segundo suplemento, de 2007, puede consultarse en http://www.sciencia.cat/suplements.htm [consulta: 13/04/2015]).

Cifuentes i Comamala, Lluís (2007), L'ús del català en les obres científiques i pràctiques a finals de l'Edat Mitjana, en Alberni, Anna (ed.), Speculum al foder, Bellcaire d'Empordà, Edicions Vitel·la, pp. 115-127. Coll, José M. (1947), El Beato Dalmacio Moner, O. P. Ensayo cronológico de su vida, sus estudios y enseñanza en la Orden Dominicana, "Annals de l'Institut d'Estudis Gironins" 2, pp. 229-243.

Colomer i Pous, Eusebi (1997), El pensament als Països Catalans durant l'Edat Mitjana i el Renaixement, Barcelona, Institut de Estudis Catalans - Abadia de Montserrat.

Cuenca i Almenar, Salvador (2005), El seny contra l'enteniment al poema 4 d'Ausiàs March, "Llengua \& Literatura" 16, pp. 33-55.

Cuenca i Almenar, Salvador (2008), La fantasia i el poema 18 d'Ausiàs March, "Llengua \& Literatura" 19, pp. 27-47.

Cuenca i Almenar, Salvador (2012), L'Ètica nicomaquea d'Aristòtil en un compendi català del segle $X V$, "Anuari de la Societat Catalana de Filosofia" 23, pp. 7-119

Cuenca i Almenar, Salvador (2013), Sobre la filosofia de l'humanista valencià Joan Serra al De contemplatione amicicie. Notes a una traducció catalana, "Scripta" 1, pp. 1-36.

Di Girolamo, Costanzo (ed.) (2004), Ausiàs March. Páginas del Cancionero, Introducción, edición y notas de Idem, traducción de José María Micó, Valencia, Pre-textos.

Faulhaber, Charles B. (2004), Semitica Iberica: translations from Hebrew and Arabic into the medieval Romance vernaculars of the Iberian Peninsula, "Bulletin of Spanish Studies" 81, pp. 873-896.

Fenzi, Enrico (2012), Lo somni di Bernat Metge e Petrarca: Platone e Aristotele, oppinió e sciència çerta, en Cabré, Lluís; Coroleu, Alejandro; Kraye, Jill (eds.), Fourteenth-century classicism: Petrarch and Bernat Metge, Londres, Warburg Institute - Turín, Nino Aragno Editore, pp. 85-108.

Fidora, Alexander (2015), Guido Terreni, O.Carm. (†1342): studies and texts, Barcelona - Madrid, Fédération Internationale des Instituts d'Études Médiévales (Textes et Études du Moyen Âge; 78).

García Ballester, Luis (1996), Naturaleza y ciencia en la Castilla del siglo XIII. Los orígenes de una tradición: los Studia franciscano y domi- 
nico de Santiago de Compostela (1222-1230), “Arbor” 604-605, pp. 69-126.

Gensler, Marek (1997), The philosophical issues in Antonius Andreae's Scriptum in artem veterem and Abbreviatio operis Oxoniensis Scoti, "Anuari de la Societat Catalana de Filosofia" 9, pp. 51-61.

Gil Fernández, Luis (2003), Formas y tendencias del humanismo valenciano quinientista, prólogo de Antonio Mestre Sanchis, Madrid, Instituto de Estudios Humanísticos.

Gómez, Francesc J. (2010), Ficció i heterodòxia en Lo somni de Bernat Metge a la llum del Liber de spiritu et anima, "Llengua \& Literatura" 21, pp. 7-54.

González, Sara (2011), Catálogo de las bibliotecas escolásticas barcelonesas en los siglos XIII y XIV, “Atalaya” 12, §§1-86 (http://atalaya.revues. org/861 [consulta: 13/04/2015]).

Gonzálvez Ruiz, Ramón (1997), Hombres y libros de Toledo, I (1086-1300), Madrid, Fundación Ramón Areces.

Grau Torras, Sergi (2014), Aristotle in the medical works of Arnau de Vilanova (ca. 1240-1311), "Early Science and Medicine" 19, pp. 236-257.

Gros i Pujol, Miquel S. (2001), La biblioteca particular del sacerdot $i$ jutge Salomó, "Revista Catalana de Teologia" 26, pp. 51-70.

Gros i Pujol, Miquel S. (2005), La biblioteca de la Catedral de la Seu d'Urgell als segles X-XII, "Acta historica et archaeologica mediaevalia" 26, pp. 101-124.

Harvey, W. Zeev (1990), L'ànima: un tema comú a Rabí Hasday Cresques $i$ Bernat Metge, "Calls" 4, pp. 53-68.

Heiple, Daniel L. (1983), The accidens amoris in lyric poetry, "Neophilologus" 67, pp. 55-64.

Hernando Delgado, Josep (1991), La transmisión de textos clásicos de la Catalunya bajomedieval. Los escritos de teoría económica. El ms. 42 de la Biblioteca del monasterio de Sant María de Ripoll, en Pecere, Oronzo (ed.), Itinerari dei testi antichi, Roma, "L'Erma" di Bretschneider, pp. 29-54.

Hernando Delgado, Josep (1995-1996), Una biblioteca privada pluridisciplinar del segle XIV. La biblioteca del jurista Ramon Vinader $(† 1351)$, "Acta historica et archaeologica mediaevalia" 16-17, pp. 9-32.

Heusch, Carlos (1992), La version catalane du Liber de pomo seu de morte Aristotelis, "Atalaya" 3, pp. 139-153.

Higuera Rubió, José G. (2001), Honor y dialéctica (sobre la representación caballeresca de Ramón Llull en el Breviculum de Tomás Le Myésier), en Fidora, Alexander; Higuera Rubió, José G. (eds.), Ramon 
Llull, caballero de la fe. El arte luliana y su proyección en la Edad Media, Pamplona, Universidad de Navarra, pp. 81-109.

Higuera Rubió, José G. (2009), La perspectiva sincrónico-diacrónica en el estudio de la recepción de las Categorías en el pensamiento luliano, "Anuario de Historia de la Iglesia" 18, pp. 393-398.

Higuera Rubió, José G. (2014), Física y Teología (atomismo y movimiento en el arte luliano), Almería, Círculo Rojo.

Hillgarth, J. N. (1971), Ramon Lull and Lullism in fourteenth-century France, Oxford, Clarendon Press.

Ibarburu Asurmendi, María Eugenia (1999), De capitibus litterarum et aliis figuris, Barcelona, Universidad de Barcelona.

Icardo, Juan Antonio (2010), La presencia de Aristóteles en Ausiàs March, en Bellveser, Ricard (ed.), La poesia d'Ausiàs March i el seu temps, Valencia, Institució Alfons el Magnànim, pp. 373-378.

Iglesias i Fonseca, J. Antoni (1996), Llibres i lectors a la Barcelona del segle $X V$. Les biblioteques de clergues, juristes, metges $i$ altres ciutadans a través de la documentació notarial (anys 1396-1475), Bellaterra, Universitat Autònoma de Barcelona (tesis doctoral).

Imbach, Ruedi (1987), Lulle face aux Averrö̈stes parisiens, en Raymond Lulle et le Pays d'Oc, Fanjeaux, CNRS - Édouard Privat, pp. 261-282.

Johnston, Mark (1978), Scholastic psychology as a literary tradition in Ausias March, "Romance Notes" 19, pp. 383-387.

Kiviharju, Jukka (1995), Las glosas del mestre Aleix de Barcelona en su edición catalana del De regimine principum de Egidio Romano y su versión navarroaragonesa, Helsinki, Academia Scientiarum Fennica.

Lafleur, Claude (1997), L'enseignement de la philosophie au XIIIe siècle: autour du Guide de l'étudiant du ms. Ripoll 109, col. Joanne Carrier, Turnhout, Brepols.

Leclercq, Jean (1949), Un tratado sobre los nombres divinos en un manuscrito de Córdoba, "Hispania Sacra" 2, pp. 327-338.

Lehmann-Hartleben, Karl (1943), Cyriacus of Ancona, Aristotle, and Teiresias in Samothrace, "Hesperia" 12, pp. 115-134.

Lloret, Albert (2013), Printing Ausiàs March: material culture and Renaissance poetics, Madrid, Centro para la Edición de los Clásicos Españoles.

Lohr, Charles H. (1967), Medieval Latin Aristotle Commentaries, "Traditio" 23, pp. 313-413.

Lohr, Charles H. (1987), Les fondements de la logique nouvelle de Raymond Lulle, en Raymond Lulle et le Pays d'Oc, Fanjeaux, CNRS - Édouard Privat, pp. 233-248. 
Lohr, Charles H. (1995), Latin Aristotle commentaries, III: Index initiorum Index finium, Florencia, Leo S. Olschki Editore.

López Alcalde, Celia (2010), El Liber de anima rationali, ¿primera obra antiaverroísta de Ramon Llull?, "Revista de lenguas y literaturas catalana, gallega y vasca" 15 , pp. 345-359.

López Alcalde, Celia (2012), Liber novus de anima rationali de Ramon Llull. Edición crítica y estudio, Barcelona, Universitat Autònoma de Barcelona (Tesis Doctoral).

López Rueda, José (1973), Helenistas españoles del siglo XVI, Madrid, Consejo Superior de Investigaciones Científicas.

Martínez Romero, Tomàs (2009), Bruni, Martí de Viciana i el pròleg a la traducció de l'Econòmica aristotèlica, "Caplletra" 47, pp. 41-54.

Mensa i Valls, Jaume (2009), Arnau de Vilanova, la filosofia i la sentència condemnatòria de les seves obres (Tarragona, 1316), "Enrahonar" 42, pp. 21-46.

Mestre, Marina (2009), El papel de la antropología augustiniana en la poesía de Ausias March, "Criticón" 107, pp. 11-27.

Minio-Paluello, Lorenzo (1972), Opuscula. The Latin Aristotle, Amsterdam, Adolf M. Hakkert.

Montoliu, Manuel de (1959), Eiximenis, Turmeda i l'inici de l'humanisme a Catalunya: Bernat Metge, Barcelona, Alpha.

Navarro Sánchez, Francisca (2009), Petri Hispani Questiones super libro De animalibus Aristotelis. Estudio, edición y traducción del ms. 1877 de la B. N. de Madrid, vol. I, Barcelona, Universitat Autònoma de Barcelona (tesis doctoral) (cf. ddd.uab.cat/pub/tesis/2009/tdx-0324110124956/fns2de6.txt; [consulta: 30/07/2014]).

Novoa, James W. Nelson (2010), Ms. Parma Pal. 2666 as a document of Sephardi literary and philosophical expression in fifteenth-century Spain, "European Judaism" 43, pp. 20-36.

Pagès, Amédée (1912), Auzias March et ses prédécesseurs. Essai sur la poésie amoureuse et philosophique en Catalogne aux XIVe et XVe siècles, París, Librairie Honoré Champion [reimpr. Ginebra, Slatkine Reprints, 1974].

Puig i Oliver, Jaume de (1978), Escriptura i actitud humanística en el Liber creaturarum de Ramon Sibiuda, "Revista Catalana de Teologia" 3, pp. 127-151.

Puig i Oliver, Jaume de (2006), El tractat Confessio fidei christianae de Nicolau Eimeric, O. P. Edició i estudi, "Arxiu de textos catalans antics" 25, pp. 7-192.

Puigvert i Planagumà, Gemma (1995), Estudi dels manuscrits científics del monestir de Santa Maria de Ripoll. Notes per a un estat de la qüestió (I), "Faventia" 17, pp. 89-118. 
Puigvert i Planagumà, Gemma (2000), Astronomia i astrologia al monestir de Ripoll: edició i estudi dels manuscrits científics astronomicoastrològics del monestir de Santa Maria de Ripoll, Barcelona, Universitat Autònoma de Barcelona.

Ramírez i Molas, Pere (1980), El problemàtic cant 128 d'Ausiàs March i la tradició manuscrita, "Estudis Universitaris Catalans" 24 [Estudis de llengua i literatura catalanes oferts a R. Aramon i Serra en el seu setantè aniversari, vol. II], Barcelona, Curial, pp. 497-512.

Ramis Barceló, Rafael (2013), En torno al escoto-lulismo de Pere Daguí, "Medievalia" 16, pp. 235-264.

Rico, Francisco (1982), Primera cuarentena y Tratado general de literatura, Barcelona, El Festín de Esopo.

Rico, Francisco (2002), Petrarca y el "humanismo catalán”, en Estudios de literatura y otras cosas, Barcelona, Destino, pp. 147-178 [=Tavani, G.; Pinell, J. (eds.), Actes del sisè colloqui internacional de llengua $i$ literatura catalanes, Roma, 28 setembre - 2 octubre 1982, Barcelona, Abadía de Monserrat, 1983, pp. 257-291].

Robles Carcedo, Laureano (1974), Escritores dominicos de la Corona de Aragón (s. XIII-XV), en Repertorio de Historia de las Ciencias Eclesiásticas en España, III: siglos XIII-XVI, Salamanca, Instituto de Historia de la Teología Española, pp. 11-177.

Robles Carcedo, Laureano (1979), Aristoteles Latinus. Repertorio de manuscritos españoles, en Actas del V Congreso internacional de filosofía medieval, vol. I, Madrid, Editora Nacional, pp. 333-460.

Robles Carcedo, Laureano (1992), Tomás de Aquino, Salamanca, Universidad de Salamanca.

Rubio, Josep E. (2009), Salvar Aristòtil? La teologia davant la cultura pagana a la tardor medieval, "eHumanista" 13, pp. 173-194.

Shwartz, Louis (2012), The Quodlibet secundum of Ferrarius Catalanus, $O$. $P$., Parisian master and successor of St. Thomas Aquinas, "Mediaeval Studies" 74, pp. 51-99.

Soler, Albert (2006), Editing texts with a multilingual tradition. The case of Ramon Llull, "Variants" 5 [Texts in multiple versions. Histories of editions], pp. 53-72.

Tubau Moreu, Xavier (1999), Textos y contextos de una polémica: Petrarca y la escolástica (o Los modernos), "Medievalismo. Boletín de la Sociedad Española de Estudios Medievales" 9, pp. 105-146.

Wingate, Sybil Douglas (1931), The mediaeval Latin versions of the Aristotelian scientific corpus, with special reference to the biological woks, Londres, Courier Press. 
Zimmermann, Michel (2003), Écrire et lire en Catalogne (IXe-XIIe siècle), 2 vols., prefacio de Pierre Toubert, Madrid, Casa de Velázquez.

Zuccato, Marco (2005), Gerbert of Aurillac and a tenth-century Jewish channel for the transmission of Arabic science to the West, "Speculum" 80, pp. 742-763.

Fecha de recepción del artículo: agosto 2014

Fecha de aceptación y version final: abril 2015 